\title{
Procesos de acumulación, industria y Pyme. El caso argentino y los límites del neodesarrollismo ${ }^{1}$
}

\section{Processes Accumulation, Industry and SMEs. The Argentine Experience and Limits of Neo-developmentalism}

\section{Processo de acumulação, indústria e Pyme. $O$ caso argentino e os limites do neodesenvolvimentismo}

\author{
Víctor Ramiro Fernández ${ }^{2}$ \\ Investigador del Consejo Nacional de Investigaciones Científicas y Técnicas \\ Santa Fe, Argentina \\ rfernand@fcjs.unl.edu.ar \\ Cristhian Rubén Seiler ${ }^{3}$ \\ Becario doctoral del Consejo Nacional de Investigaciones Científicas y Técnicas \\ Santa Fe, Argentina \\ cseiler@fcjs.unl.edu.ar
}

Recibido: 08/05/2015

Aprobado: 24/11/2015

1 Este trabajo es una versión cualificada de la ponencia presentada en el VI Congreso Anual de la Asociación Económica para el Desarrollo Argentino en la Universidad Metropolitana para la Educación y el Trabajo en Buenos Aires los días 19 y 20 de mayo de 2015. Es un resultado parcial de una investigación en curso enmarcada en el proyecto CAI+D 2011 Estructuras estatales y política pública orientada a pyme y desarrollo en la Argentina posconvertibilidad (2002-2012), financiada por la Universidad Nacional del Litoral.

2 Doctor en Ciencia Política y Posdoctor en Geografía.

3 Licenciado en Ciencia Política. 


\title{
Resumen
}

Este artículo introduce la discusión acerca del papel de las pequeñas y medianas empresas (Pyme) y el sector industrial en los procesos de acumulación en Latinoamérica a principio de siglo XXI. Señalando el dominio de la lógica neoliberal del capital globalizado, reconoce los requerimientos y desafíos que pesan sobre el sector industrial y los actores pyme para la construcción - disputada- de un patrón de acumulación posneoliberal en los recientes proyectos neodesarrollistas. En este marco conceptual, se evalúa críticamente el desempeño económico (interno y externo) de la industria y las Pyme en el caso argentino (2002-2012), dando cuenta de su alineamiento a un patrón de acumulación que, en compatibilidad con la lógica del capital global, no altera su condición periférica profundizada bajo el Consenso de Washington.

Palabras clave: procesos de acumulación; pyme; industria; neodesarrollismo; posneoliberalismo.

\begin{abstract}
This paper introduces the discussion on the role of small and medium enterprises (SMEs) and the industrial sector in the accumulation processes in Latin American in the XXI century. Underlining the pressure of the neoliberal logic of global capital, it recognizes the requirements and challenges that weigh on the industry sector and the SMEs to the construction of a post-neoliberal accumulation pattern in recent neo-developmentalism projects. Based on this framework, it critically evaluates the Argentina's experience (20022012) observing the industry and SME (internal and external) economic performance. This performance shows their alignment with an accumulation pattern that is compatible with the global capital's logic, and does not alter its peripheral position deepened under the Washington Consensus.
\end{abstract}

Keywords: accumulation processes; SMEs; industry; new developmentalism; post-neoliberalism.

\section{Resumo}

Este artigo introduz a discussão sobre o papel das pequenas e médias empresas (Pyme) e o setor industrial nos processos de acumulação em América Latina, nos começos do Século XXI. Salientando o domínio da lógica neoliberal do capital globalizado, reconhece-se os requisitos e desafios que pesam sobre o setor industrial e sobre os atores pyme na construção -disputada- de um padrão de acumulação pós-neoliberal, nos recentes projetos neodesenvolvimentistas. Nesse marco conceitual, avalia-se criticamente o desempenho econômico (interno e externo) da indústria e as pyme no caso argentino (2002-2012). Se enfatiza o alinhamento a um padrão de acumulação que sendo compatível com a lógica do capital global, não altera sua condição periférica, robustecida pelo Consenso de Washington.

Palavras-chave: processo de acumulação; pyme, indústria; neodesenvolvimentismo, pós-neoliberalismo. 


\section{Introducción}

El presente artículo tiene por objeto resituar la discusión acerca del papel estratégico de las pequeñas y medianas empresas (pyme) y el sector industrial en los procesos de acumulación en Latinoamérica a comienzo del siglo XXI. Se propone examinar el comportamiento, las limitaciones y potencialidades de ese sector y esos actores en el marco de la disputada configuración de los patrones de acumulación (PA) que acompañan la emergencia de los proyectos neodesarrollistas surgidos en Latinoamérica - particularmente en Argentinay el debate sobre el carácter posneoliberal del escenario en el que se inscribe esa reemergencia.

Para ello, se introduce una perspectiva conceptual que analiza el posicionamiento y el papel del sector industrial y de las pyme en el marco de la disputada construcción del PA —en el cual se emplazan- resultante de dos lógicas contradictorias que configuran la arquitectura y geometría de las dinámicas internas de acumulación: por un lado, la lógica impulsada desde las fracciones globalizadas del capital global, y por otro, la que marca los requerimientos alternativos que demanda un escenario de desarrollo neodesarrollista genuinamente posneoliberal. Reconociendo el carácter conflictual que ello plantea, sostenemos que la conformación de un PA necesario para sustentar el desarrollo latinoamericano -y argentino en particular-contiene determinados requerimientos (en su composición, su lógica y actores) que confrontan con las formas y estructuras de acumulación global desplegadas por las empresas transnacionales (ET) que controlan las redes económicas globales (REG). Distinguimos, en tal sentido, aquellas propiedades derivadas de la acción conformadora de estos actores, que recrean la lógica neoliberal de mercantilización propia del Consenso de Washington (CW); respecto de aquellas propiedades alternativas, requeridas para dar sentido y precisión a un proyecto neodesarrollista bajo el que se conforme una modalidad capaz de lograr una forma posneoliberal más igualitaria de desarrollo.

Realizando una serie de precisiones teóricas y conceptuales acerca de la definición de estas propiedades, destacamos la necesidad de una mayor complejidad, densidad y dinamismo de las estructuras productivas, en las que la industria en general y las pyme en particular adquieren un carácter estratégico. Examinamos la forma en que ese sector y esos actores - y las dinámicas y estructuras internas relacionadas - condicionan la conformación de un determinado PA y al mismo tiempo son condicionados por él. Las propiedades alternativas no solo actúan en una contradirección a la modalidad subalterna, marginal y fragmentadora impulsada desde las REG (que profundizan la desigualdad y heterogeneidad estructural), sino que centralmente contribuyen a construir un proceso más autónomo de integración socio-espacial con mayor inclusividad y homogeneidad (estructural) en lo interno, y una inserción más cualificada y menos subalterna en lo externo.

El abordaje del papel de las pyme dentro de este marco y su contribución a la formación de esas propiedades requiere trascender su tradicional consideración como generadoras de empleo y/o centrada en su importancia numérica (Cepal/ Ocde 2012). Implica valorarlas más cualitativamente como actores desafiados a 
actuar dinámicamente a partir de conformar una red articulada y compleja internamente capaz de disputar la retención de mayor valor agregado a través de su participación en las actividades y funciones más relevantes de la producción global, como también de formar una base actoral estratégica que relativice las formas obstaculizadoras asociadas a la renta de recursos naturales y/o financieras propias del capital concentrado.

A partir de estas claves conceptuales, situamos nuestra mirada sobre la dinámica industrial en general y las pyme en particular en Argentina en la década 2002-2012, observando las continuidades y/o cambios del PA y su contribución a la formación de un escenario de acumulación posneoliberal. Al avanzar en dicho análisis, señalamos la falta de concreción de una transformación del PA a través de un involucramiento más cualificado del sector industrial y las pyme. Los resultados muestran que hemos asistido a un PA más bien compatible con $-\mathrm{y}$ resultante de-las lógicas e intereses reproductivos del capital concentrado, donde el sector industrial y los actores pyme no abandonan el rol visiblemente marginal y subalterno que les asignó el proyecto neoliberal.

El artículo se organiza en tres partes. En la primera se establece conceptualmente el esquema conflictual que plantea la dominancia de los actores transnacionales con sus condicionantes sobre las dinámicas del PA y las pyme en los países periféricos latinoamericanos. En la segunda se presentan las precisiones conceptuales sobre la forma en que el sector industrial y las pyme pueden contribuir en la alteración y cualificación del PA y la construcción de una trayectoria posneoliberal de desarrollo. En la tercera, tomando el caso argentino como ilustrativo de nuestra argumentación teórica, realizamos una caracterización y análisis de la dinámica industrial y de las pyme a la luz de los requerimientos posneoliberales planteados.

\section{Desarrollo, patrón de acumulación y pyme}

En esta sección presentamos los resultados poco alentadores que las dinámicas de las REG - y su comando transnacional- promueven sobre las dinámicas del $\mathrm{PA}^{4}$ en los países latinoamericanos, y cómo ello impacta específicamente en lo relativo al posicionamiento de las pyme. Marcada esa escena, en la segunda sección avanzaremos en presentar una configuración alternativa de acumulación, que propicie una modalidad socio-espacial más integradora de desarrollo a través de conformar un PA con mayor autonomía para definir internamente los procesos de incorporación socio-espacial como para determinar las formas o alternativas de inserción externa más sofisticadas y dinámicas. Por tanto, comprender la relevancia de esta autonomía y dar cuenta del papel a desempeñar allí por las pyme demanda:

4 A los fines de este artículo, entendemos por patrón de acumulación (PA) al conjunto de actividades económicas y actores que motorizan el proceso de acumulación capitalista y le imprimen una cierta regularidad, dotándolo de una determinada estructura y dinámica de valoración del capital (Basualdo 2006). 
i) considerar la forma en que el capital global ha reconstituido su lógica reproductiva y su impacto sobre las estructuras industriales periféricas y las pyme; ii) considerar los fundamentos de esa mayor autonomía y de los componentes antes mencionados del PA para dar soporte y consistencia a una alternativa posneoliberal frente a la trayectoria de dependencia histórica del PA latinoamericano;

iii) evaluar el rol de las pyme como una base socio-actoral estratégica en el marco de dicha construcción.

\subsection{Redes económicas globales, patrón de acumulación y pyme en Latinoamérica}

La emergencia de las formas de acumulación más flexible que tuvo lugar después de la crisis de la década de 1970 (Piore y Sabel 1984), junto a la redinamización del crecimiento a través de la lógica aperturista de las economías nacionales, tuvo dos efectos cualitativos relevantes: por una parte una profundización del desarrollo desigual global (Harvey 2004) y, por otra, una alteración en las formas de producción y realización del capital centrada en la configuración de REG que atravesaron crecientemente las formas nacionales dominantes de posguerra (Dicken et al. 2001).

Posibilitada por las tecnologías de la información y la comunicación, la creciente capacidad que adquirieron estas redes de operar - a través de un proceso estratégico de descentralización y multilocalización de la producción de bienes y servicios, y de recentralización decisora de esas estrategias (Sassen 2010)— dotó a una fracción de capital global conformada por las ET con la capacidad de gobernar y coordinar globalmente la organización de los procesos productivos a través de diferentes modalidades de gobernanza (Gereffi, Sturgeon y Humphrey 2005).

Esta capacidad de coordinar los procesos productivos crecientemente fragmentados espacial y funcionalmente en el mundo, opera como una fuente centralizada de beneficios que hace uso de dicha fragmentación y selectividad productiva de los factores - bajos costos de la materia prima y la mano de obra, infraestructura, etc.- en la conformación de esas redes (Gereffi, Sturgeon y Humphrey 2005). El éxito de las empresas y/o de las estructuras productivas -crecientemente fragmentadas - pasa a depender cada vez más del modo — selectivo- de su inserción económica y el posicionamiento dentro de esas redes, así como de la eficacia de sus propias estrategias implementadas para mejorar cualitativamente ese posicionamiento (Dicken et al. 2001; Levy 2008). Este mejoramiento (upgrading) no siempre es incompatible con la estructuración que promueven las empresas líderes (governance) sobre las REG, ya que bajo determinadas formas de gobernanza (jerárquicas o cuasi jerárquicas) las empresas/clusters de empresas obtienen espacios de ascenso en productos y/o procesos obteniendo mayores beneficios dentro de la cadena (Humphrey y Schmitz 2002). Sin embargo, este ascenso encuentra tarde o temprano límites estructurales al momento de realizar un desplazamiento funcional dentro de la cadena hacia actividades de mayor valorización. La disputa se entabla aquí solo si las empresas/clusters en ascenso — funcional- poseen suficiente capacidad (estructural y/o sistémica) 
para transitar hacia las actividades más valoradas como la comercialización, el diseño y/o el marketing que son retenidas por las empresas líderes (Sela 2012; Humphrey y Schmitz 2002; Fernández 2015; Kaplinsky 2000).

Ahora bien, frente a las heterogéneas condiciones de partida y trayectorias de desarrollo de los países capitalistas (Dicken et al. 2001), el nuevo escenario ha viabilizado el argumento de quienes sostienen que para aquellos países que no controlan las actividades centrales de las REG resulta más provechoso ingresar a cadenas de valor ya construidas y desarrollar dinámicas industriales utilizando las opciones y beneficios - ej. bajo costo de insumos y equipos- que ofrecen los proveedores globales (Baldwin 2011). Esta estrategia, denominada "ganar-ganar" (win-win) de ingreso rápido a las REG, oculta los efectos destructivos y desintegradores sobre las cadenas de valor locales que se expresan principalmente en la destrucción de los empleos (Sela 2012). Por tanto, la calidad del ingreso a las REG es un factor crítico sobre el cual pesa el giro desde la idea de un proceso "rápido y poco profundo" de industrialización hacia una opción "lenta, pero localmente densa y compleja" que implica el despliegue de estrategias y recursos, integralmente articulados, orientados a construir procesos y encadenamientos regionales y nacionales más sofisticados y densos.

Comprendiendo los efectos estructurales que en términos de poder impone aceptar la selectividad en las funciones de comando y apropiación desigual de valor (Levy 2008), el campo propositivo esconde una integración invariablemente subalterna a estas redes y su participación aconflictual en los procesos de neoliberalización liderados por las ET que, centralmente, se fundan en la extensión -espacial- sin límites de los procesos de mercantilización (Peck 2010; Fernández 2015). Esa subalternidad puede traducirse tanto en un proceso de "acoplamiento pasivo" (a través de ventajas estáticas) o bien —en el mejor de los casos- en uno de "integración activa" en segmentos dinámicos pero en el marco de funciones y actividades estratégicas controladas por las ET.

Esta subalternidad también ha sido abonada por un contexto de fuertes presiones hacia la financiarización de las prácticas y estrategias en el seno de las REG (Milberg 2008; Newman 2009). Los procesos de transferencia y aprendizaje tecnológico y productivo pasan a un segundo plano frente al componente especulativo y/o cortoplacista del capital financiero que, en el contexto latinoamericano, ha estado escasamente vinculado a los procesos productivos (Fernández 2015).

Ahora bien, no obstante el éxito de algunas experiencias de ascenso sucedidas en las últimas décadas en la región del sudeste asiático $(E A)^{5}$ mediada por un PA industrialmente dinámico y endógeno con una importante participación en las actividades y funciones estratégicas, el despliegue de las REG en los escenarios periféricos se ha caracterizado por su capacidad de proponer una integración subordinada a través de los eslabones de menos agregación de valor y retener en el centro - base de las ET que las comandan- las funciones estratégicas de mayor valoración (Kaplinsky 2000).

5 Nos referimos puntualmente a las experiencias de Japón, Corea del Sur, Taiwán y Singapur —con el incierto futuro de China — dentro de una macrorregión por cierto no homogénea. 
Particularmente, en el contexto latinoamericano estos procesos convergen, en términos generales, en la conformación de un PA sujeto a una lógica que no estimula la industrialización compleja, sofisticada y articulada. O, en todo caso, resulta promotora de una industrialización "nacionalmente trunca" (Fajnzylber 1983b), limitada en su extensión y diversificación debido al carácter fragmentario y subalterno de la integración y al escaso liderazgo en innovación, aprendizaje y construcción de capacidades tecnológicas (Cimoli 2005) al que quedan sometidos los actores y estructuras locales. En otras palabras, las prácticas alentadas desde las ET transitan por un reforzamiento o inalterabilidad de esa condición periférica y que abona la carencia de autonomía para el impulso de procesos más complejos y diversificados que ataquen la heterogeneidad social, productiva y espacial (Fajnzylber 1983b; 1972) y viabilicen en estas latitudes dinámicas más inclusivas e igualadoras de acumulación.

En tal contexto, observando los resultados adversos anteriormente indicados sobre las estructuras y dinámicas productivas internas, ello es más evidente aún sobre la heterogénea trama pyme de los países latinoamericanos (Cepal/OCDE 2012). Si bien estas fueron consideradas centralmente tanto en el marco de los nuevos espacios de producción como de las formas más flexibles de acumulación (Piore y Sabel 1984) y, así mismo, los OI soportan su centralidad a través de iniciativas de construcción de competitividad e inserción global (UNCTAD 2010; Pietrobelli y Rabellotti 2006; Stezano 2013), no pueden escapar, aún en su papel más proactivo - colectivo/asociativo-, a la conformación de procesos nacionales atravesados y condicionados por el dominio de la exclusión y la subalternidad fragmentadora propia de las REG que afecta los procesos de upgrading ${ }^{6}$ (Humphrey y Schmitz 2002; Sela 2012).

De manera que, en el contexto periférico latinoamericano esta dinámica resulta en la conformación de dos escenarios poco alentadores que marcan grandes desafíos para cualificar la inserción internacional de las pyme y las dinámicas internas de acumulación:

a) Uno de no integración de las pyme a la economía global: el escenario latinoamericano muestra que su participación en los mercados externos ha sido, en términos comparativos, marcadamente restringida respecto a los países centrales $^{7}$ (Sela 2012; Stezano 2013), al tiempo que encuentran en los mercados internos las restricciones propias de los procesos de transnacionalización y concentración económica.

b) Otro, en el que aún integradas a las REG encuentran límites que se refieren, por un lado, a no alcanzar funciones estratégicas dentro de las REG, ya que siguen siendo retenidas por las ET en sus casas matrices, restringiendo el aprendizaje y la innovación local; y por otro, debido a la escasa profundidad,

6 Puede consultarse para el caso argentino el análisis del Programa de Consorcio de Exportación en Bekerman, Wiñazky y Moncaut (2013); para el caso brasileño puede consultarse un análisis más general del desempeño las pyme y los resultados del Grupo de Trabajo Permanente para Aglomeraciones Productivas Locales (GTP-APL) en De Matos y Arroio (2011).

7 En América Latina y el Caribe la producción y las exportaciones están concentradas en grandes empresas. Si bien la información estadística acerca de la participación de las pyme es escasa, la disponibilidad de datos indica que el espectro exportador está dominado por grandes empresas en donde las pyme participan alcanzando solo 10\% en general (SELA 2012). 
complejidad y densidad que el proceso de industrialización por vinculación a las REG promueve sobre las estructuras nacionales.

\subsection{Trayectoria y desafíos del PA en el contexto Latinoamericano}

En este marco, uno de los elementos centrales que este trabajo propone introducir es que dicho escenario desfavorable para las pyme no solo encuentra fundamento en las "restricciones" desde las REG, sino que internamente, la configuración histórica y disputada del PA no ha propiciado la construcción de una matriz industrial densa y articulada que opere como sustento de una presencia interna y externa más notable y cualificada de las pyme ${ }^{8}$.

En primer lugar, la agresividad y presión del capital financiero encontraron en la desarticulación de la industrialización sustitutiva de importaciones (ISI) (principalmente en Argentina, Brasil, y México) un momento estratégico de condicionamiento (Salama 2006) e integración a la economía global en un camino de regreso al pretérito esquema de la división internacional del trabajo (Robinson 2008; Fajnzylber 1983b). En segundo lugar, ciertas restricciones del modelo ISI abonaron la imposibilidad de consolidar una base industrial endógena y dinámica —como sí logró hacerlo el EA (Fajnzylber 1987)—, esencial para superar la heterogeneidad socio-productiva (Mancini y Lavarello 2013) como la concentración de la renta que provocaba el frecuente estancamiento económico (Furtado 1974; Pinto 1970). Su énfasis mercado-internista y corporativo-distributivo antes que productivo y centrado en la competitividad sistémica (Esser 1993), desató problemas económicos estructurales ligados a la balanza de pagos y tensiones internas en las que operaron fuertes relaciones de poder. Como corolario de ello, las resoluciones autoritarias experimentadas en buena parte de la región -y agravadas por la crisis de la deuda externa iniciada la década de 1980interrumpieron abruptamente la estrategia ISI (O’Donnell 2009; Kaufman 1985). Luego del interregno dictatorial, donde toma lugar el modelo de valorización financiera y paradójicamente instalado en un escenario de retorno a la democracia, los organismos internacionales (FMI-BM) impulsaron en Latinoamérica un proceso disciplinador basado en los postulados neoliberales, donde la Argentina se erigió como experiencia paradigmática por las transformaciones llevadas a cabo (Basualdo 2006; Azpiazu, Basualdo y Schorr 2001; Azpiazu y Schorr 2010a).

El resultado de su implementación implicó -entre otras cosas- un fuerte avance del capital transnacional, expresado en un generalizado proceso de "acumulación por desposesión" (Harvey 2004) que abonó a la desarticulación de las dinámicas nacionales y regionales de acumulación orientando la estructura económica a proyectarse como proveedor de recursos naturales, donde la Argentina cuenta con ventajas naturales. Además, la proliferación de "ámbitos privilegiados de acumulación" (Castellani y Gaggero 2012), como el desplazamiento del capital concentrado y las ET a sectores "tradicionales" de la economía — por cierto, donde radican esas ventajas naturales - fueron debilitando el incompleto

8 En Argentina, el pequeño y mediano capital nacional solo ha tenido centralidad en los inicios de la estrategia sustitutiva (Féliz 2013). 
carácter industrial del PA y profundizando su reprimarización fomentada por la combinación concentración-extranjerización (Féliz 2014). Ello puso en notable evidencia la falla del nivel actoral que estructura el PA —concentrado y exógeno- que, desde mediados de la década de 1990, hubo un desplazamiento de los grandes grupos económicos locales de la escena industrial, pero más duramente de innumerables pyme (Azpiazu, Basualdo y Schorr 2001; Castellani y Schorr 2004) 9 .

Ahora bien, continuando con nuestro razonamiento, de este desarrollo resulta central comprender que la trayectoria y configuración histórica del —disputado- PA, estructuralmente, tanto los sectores que asumen protagonismo como los actores que los motorizaron coagulan un determinado escenario de acumulación — vale recordar: concentrado y exógeno que es funcional a las REG-, donde el sector industrial y particularmente las pyme toman un papel secundario interna y, más aún, externamente. De este modo se comienza a advertir la necesidad de que la problemática pyme — sus limitaciones y comportamientos - sea abordada en el marco de las condiciones de ambos escenarios conflictivos - REG y PA- sobre los que toma lugar.

\section{Reacción neodesarrollista y carácter posneoliberal del patrón de acumulación}

Ahora bien, frente al agotamiento del proceso de acumulación bajo el proyecto del CW y el deterioro de las condiciones materiales de reproducción social de la población (altos niveles de pobreza, indigencia, desempleo, etc.) (Cepal 2005) tuvo lugar, en forma bastante generalizada en Latinoamérica, un conjunto de reacciones y proyectos políticos que hicieron frente a dichos resultados (Sader 2008). Si bien se pueden detectar diferencias entre las experiencias más asociadas a formas alternativas de encarar el agotamiento neoliberal (p. ej. Bolivia), resulta importante considerar los casos de Argentina, Brasil y México con similitudes pasibles de generalizaciones.

En Argentina, particularmente luego del interregno crítico de 1998-2001 donde se puso en evidencia la inconsistencia del modelo neoliberal (centrado en la paridad cambiaria $\$ 1=$ US\$1), el Estado tomó un papel protagónico en la tarea de recomponer y sostener el proceso de acumulación, haciendo compatible el crecimiento económico con la inclusión social (Grugel y Riggirozzi 2007; 2012). Aunque la forma que este nuevo posicionamiento estatal asumía en la formación de una alternativa ubicada en las antípodas del neoliberalismo - revalorizando el "capitalismo nacional" — - lo cierto es que la base de poder de la reacción neodesarrollista estuvo centrada en buena medida en las fracciones de clase que habían sustentado el proyecto neoliberal (Féliz 2015). La

9 Aquí, cobra especial importancia la discusión acerca del rol del capital extranjero y la idea de que su inserción beneficiaría a los países en desarrollo difundiendo cambios e innovaciones tecnológicas. Pueden consultarse trabajos puntuales (Wainer y Schorr 2014) o más generales (Sunkel 1971), la evidencia sugiere que es una idea difícil de probar.

10 Ese fue el espíritu de los primeros mensajes del presidente Néstor Kirchner luego de asumir la Presidencia de la Nación en 2003. 
salida de la crisis vía devaluación " desempeñó un rol fundante en el reacomodo y fortalecimiento de las posiciones del capital concentrado - nacionales y extranjeros-, commodities dependientes y ansioso de salarios reales deprimidos (Castellani y Schorr 2004). En otras palabras, el PA fomentado por el proyecto neodesarrollista - argentino en particular- arrastraba internamente las contradicciones que profundizaron su condición periférica bajo el CW.

Frente a más continuidades que rupturas con el CW, ello nos ha animado a abordar algunos elementos pocos precisados académica y políticamente acerca de las implicancias de construir una alternativa de acumulación capitalista posneoliberal en el contexto latinoamericano. Estas precisiones advierten primeramente que la continuidad de procesos de inclusión social, inaugurados por las experiencias neodesarrollistas, colisionan con las contradicciones propias de las estructuras periféricas de acumulación - baja productividad relativa y sustentada en las ventajas naturales, etc.- que no permiten sostener a largo plazo un formato nacional-popular de sociabilidad (Prebisch 1981). Incorporando dichos elementos, nuestro razonamiento transitará en reconsiderar el pensamiento estructuralista y neoestructuralista a la luz de una perspectiva crítica sobre los actores de la transformación, donde la presencia de pyme encuentra asidero estratégico para alterar las características del PA.

El razonamiento que seguiremos es el siguiente. Un PA dinámico, diversificado y complejo centrado en el sector industrial y sobre el cual enarbolar una resistencia e inserción más cualificada y autónoma en las REG encuentra en las pyme un actor de gran relevancia para su construcción. En tal sentido, un PA posneoliberal no solo demanda al sector industrial como pilar fundamental e insoslayable de progreso técnico, sino también un lugar estratégico de las pyme para la construcción de encadenamientos y complementariedades. Frente a la fórmula concentración/ extranjerización/reprimarización, el protagonismo de las pyme conlleva la posibilidad de construir una modalidad más sostenible y descentrada de acumulación, que eleve el margen de agregación y retención de valor en y para los espacios nacionales y macro y subregionales.

\subsection{Cualificación del patrón de acumulación}

\subsubsection{Centralidad del sector industrial}

Como ampliamente se ha establecido en la literatura académica, principalmente latinoamericana, la superación de las brechas tecnológicas, de productividad y competitividad con los países centrales implica revalorizar el argumento que hace de la cualificación del PA a través de su carácter industrial el epicentro dinámico sobre el cual se edifica un proceso de creación, retención, distribución y apropiación del excedente más endógeno y más igualitario socialmente en el ámbito nacional (Cepal/Ocde 2012; Prebisch 1986; Sela 2012; Cimoli 2005; Cimoli,

11 Respecto a la discusión entre devaluación versus dolarización como formas alternativas de salida para el agotado modelo de acumulación neoliberal, puede consultarse Salvia (2014) y Basualdo (2002) o el trabajo de Castellani y Schorr (2004). 
Dosi y Stiglitz 2009). Ello no solo ha sido una de las preocupaciones centrales del pensamiento estructuralista latinoamericano y de los recientes debates sobre cambio estructural e igualdad (Cepal/OCDE 2012; Cepal 2012), sino que se ha constituido - en la práctica - en la base de los procesos de desarrollo del EA (Amsden 2001; 2004).

El aumento de la proyección y relevancia del sector industrial - manufacturero, principalmente los intensivos en conocimiento- en la estructura productiva no solo reviste importancia histórica al dar lugar al ascenso en la jerarquía mundial de los países del EA (Amsden 1989; 2001), sino por la promoción de la igualación social que promueve a través del achicamiento de las brechas salariales (Cepal 2012). En términos del impacto estructural, el elemento estratégico del sector industrial se centra en la capacidad de incorporar y difundir el progreso técnico al resto de los sectores y actividades (Prebisch 1986) disminuyendo los desequilibrios estructurales de productividad dentro del sistema económico (Diamand 1972, Pinto 1976) y reduciendo las brechas tecnológica, productiva y de ingresos frente a los países centrales (Cepal/OCDE 2012; Cimoli, Dosi y Stiglitz 2009; Fajnzylber 1972; 1983a; 1992; Prebisch 1986). De igual manera, esa capacidad posee una relación virtuosa con el tránsito de una "imitación grotesca" de la tecnología hacia el "aprendizaje creativo" con mayor autonomía y autodeterminación nacional (Amsden 1989; Fajnzylber 1983a) centrado en el desarrollo y acumulación de capacidades tecnológicas como resultado de mayor presencia de sectores intensivos en conocimiento (Cimoli, Dosi y Stiglitz 2009).

En los últimos años, el rol de las manufacturas ha ido adquiriendo nuevamente un lugar importante en las economías centrales, en línea con la advertencia de su importancia frente al advenimiento de una supuesta sociedad posindustrial (Cohen y Zysman 1987; Bell 1976). De hecho, en la última década Estados Unidos ha mostrado un vital interés por el sector manufacturero como una herramienta clave para la reactivación y estabilización de la economía (Tyson 2012).

\subsubsection{Centralidad de las pyme: endogeneidad y dinamismo en el patrón de acumulación}

Ahora bien, el reposicionamiento del sector industrial como elemento central del cambio de propiedades del PA presenta un marco problemático inmanente en cuanto a los actores que lo motorizan. Un PA alternativo con dinámicas más endógenas de creación, retención, distribución y apropiación del excedente requiere inevitablemente una matriz socio-actoral alternativa propensa a desarrollarlas. Evitar reproducir los PA periféricos centrados en la búsqueda de renta sin innovación (prácticas comunes del capital concentrado) requiere conformar una coalición de actores e intereses portadora de una relación de fuerzas suficiente para quebrar inercias rentistas fuertemente arraigadas e introducir —no marginal sino estructuralmente- formas productivas más articuladas y complejas, propugnadoras de prácticas colectivas de innovación y aprendizaje tecnológico que densifiquen el PA.

Lo sucedido en las experiencias del EA marcan cierto contraste con las experiencias latinoamericanas (Argentina, Brasil, México) respecto a su capacidad 
de complejizar las estructuras internas de acumulación (Fajnzylber 1987). Allí, la expansión de la "industrialización tardía" corrió por las vías de la construcción de un PA actoralmente endógeno y dinámico de base nacional donde el capital transnacional fue subordinado a las dinámicas internas de acumulación (Amsden 2001; Wade 1999). Si bien la construcción de ese PA tuvo lugar en condiciones socio-históricas y geopolíticas particulares (Pempel 1999), es importante destacar que la lógica de acumulación se dio a través de movilizar a los actores internos orientándolos a sectores dinámicos. Con sus especificidades, el EA logró construir endogeneidad y dinamismo simultáneamente: en Corea del Sur a través de los grandes actores diversificados (chaebol); en Japón presentó una sólida combinación a través de una compleja articulación entre grandes empresas (zaibatsu) y pyme (aprovechando gran parte del sector informal); y en Taiwán (el caso más paradigmático) logró un entramado desconcentrado de protagónicas pyme (Amsden 2001). No debemos olvidar aquí la reforma de la propiedad de la tierra (Kay 2002) y una implicación estatal con capacidad de direccionar internamente el proceso acumulativo y conformar paralelamente el PA —endógeno y dinámico- junto a los actores capitalistas que lo motorizarían (Amsden 1989; Kohli 2004; Jenkins 1991).

En Latinoamérica, las fallidas experiencias de reforma agraria (Kay 2002), así como la exigua institucionalidad y autonomía del Estado (Faletto 2014; Furtado 1974; Jenkins 1991), propiciaron la perniciosa articulación entre la concentración del capital y la renta, su retroalimentación con el capital transnacional y su tendencia a la búsqueda de renta sin cambio tecnológico (Shapiro y Moreno-Brid 2014). La penetrante presencia de estas particularidades históricas en las restricciones del PA actual demandan para su superación la construcción de una base coalicional de actores, que (bajo determinados condicionamientos desde el Estado) impulse alternativamente un PA más endógeno y desconcentrado, y propensa a profundizar un mayor dinamismo industrial. En esa construcción, las pyme revisten un papel estratégico, sin que ello implique colocarlas como actores excluyentes en la construcción del PA (como ha sido la excepcionalidad del caso taiwanés). La presencia sustantiva de las pyme en esa construcción introduce la posibilidad de relativizar el "poder de veto" del capital concentrado, a la vez que proporciona mayor margen de maniobra y direccionalidad interna al Estado al momento de orientar y condicionar los desempeños internos y externos de los actores económicos.

Al tiempo que se logre articular con grandes actores -nacionales y/o extranjerosmediando procesos de innovación y aprendizaje tecnológico, la importancia de las pyme también radica en su capacidad de operar en forma expandida territorialmente, difundiendo el progreso técnico y densificando las tramas productivo-regionales (Fernández, Alfaro y Brasca 2011), logrando una mejor distribución espacial y actoral del ingreso, así como sosteniendo el arraigo regional de la población a través de su potencial de empleo evitando su migración hacia los grandes centros urbanos (Cepal/OCDE 2012).

En el contexto posfordista de acumulación, la revalorización y el fortalecimiento de las pyme brinda un soporte socio-actoral y espacial estratégico para contrarrestar el modelo intensivo en recursos naturales del capital concentrado, y posibilita una proyección nacional de autodeterminación y construcción de redes 
económicas regionales y macrorregionales sustentadas en la complejidad, densidad y capacidad actoralmente endógena para ingresar por las vías altas — de mayor valor agregado- a las REG. En otras palabras, ello alcanza relieve suficiente en tanto las estructuras productivas adquieran complejidad y dinamismo interno en la elaboración de paquetes tecnológicos que traccionen hacia adelante y atrás, antes que productos diferenciados basados en ventajas estáticas (Sela 2012).

Bajo el desenvolvimiento de esta dinámica, que por cierto no emerge espontáneamente (Amsden 2001; Hikino, Amsden y Wolfson 1995), el PA solventaría dos aspectos cualitativos centrales en la superación de las debilidades estructurales latinoamericanas: dinamismo e inclusividad.

El dinamismo sería advertido en la presencia organizada y articulada de las pyme en torno al sector industrial para complejizar y sofisticar los entramados productivos y producir procesos colectivos de innovaciones que garantizan el carácter dinámico del PA (Fajnzylber 1983b; Piore y Sabel 1984; Fernández, Alfaro y Brasca 2011). Asimismo, orientando esa estructura hacia sectores de mayor agregado de valor (tecnológicamente avanzados e intensivos en conocimiento) aportarían una influencia exponencial al conjunto de la estructura económica desencadenando mayor dinamismo en los agregados de productividad de los distintos sectores y actores mediante el aprendizaje y acumulación de capacidades tecnológicas (Cimoli, Dosi y Stiglitz 2009). La construcción de ese dinamismo daría lugar a sostener más estratégicamente el carácter inclusivo del PA que actúa no solo por la reducción de los niveles de heterogeneidad estructural (Pinto 1970; Rodríguez 1998) y del ingreso — propios de los países periféricos (Prebisch 1981)—, sino además haciendo descender los niveles de informalidad, mucho más marcado en el sector de las pyme ${ }^{12}$ que, en buena medida, funda la permanencia de la desigualdad social.

A modo de resumen, se presentan en la tabla 1 las principales características de los PA divergentes que estilizadamente refieren, por un lado, al resultante de la acción conformadora de las REG y funcional a ellas (patrón de acumulación periférico), y por otro lado, el que consideramos como alternativo con centralidad de las pyme y del sector industrial con capacidad de disputar lugares altamente valorados en las REG (patrón de acumulación alternativo/autónomo).

Luego de presentar nuestro enfoque, donde el mejoramiento cualitativo del lugar de las pyme radica en solicitarle un cambio de propiedades al PA (en el que las pyme poseen un papel fundamental), observaremos cómo bajo el neodesarrollismo argentino la permanencia de un PA periférico con un sector industrial con dificultades estructurales propició la subalternización de las pyme. El análisis empírico remite a verificar los aspectos señalados en la tabla 1 durante la década 2002-2012.

12 En América Latina y el Caribe, si bien el desempleo urbano bajó a mínimos históricos de 6,2\% en 2013, y aunque la informalidad también descendió, es persistente y sigue afectando a $47,7 \%$ de los trabajadores ocupados. Según estimaciones de la Oficina Internacional del Trabajo, al menos $60 \%$ de los trabajadores en las micro y pequeñas empresas en América Latina y el Caribe están empleados en condiciones de informalidad (OIT 2014). 
Tabla 1. Patrón acumulativo de inserción periférica y patrón acumulativo de inserción alternativa/autónoma

\begin{tabular}{|c|c|c|c|}
\hline $\begin{array}{l}\text { Sector } \\
\text { económico }\end{array}$ & Características & $\begin{array}{c}\text { Patrón de acumulación } \\
\text { periférico }\end{array}$ & $\begin{array}{l}\text { Patrón de acumulación de } \\
\text { inserción alternativa/autónoma }\end{array}$ \\
\hline \multirow{4}{*}{ Industria } & Origen del capital & Mayoría extranjero & Mayoría endógeno \\
\hline & $\begin{array}{l}\text { Estructura del } \\
\text { capital }\end{array}$ & Concentrado & Desconcentrado \\
\hline & $\begin{array}{l}\text { Desempeño } \\
\text { interno }\end{array}$ & $\begin{array}{l}\text { Participación decreciente en } \\
\text { el PBI. Orientado al } \\
\text { procesamiento de recursos } \\
\text { naturales }\end{array}$ & $\begin{array}{l}\text { Participación creciente en el PBI, } \\
\text { actividades industrialmente } \\
\text { dinámicas e intensivas en } \\
\text { conocimiento }\end{array}$ \\
\hline & $\begin{array}{l}\text { Desempeño } \\
\text { exportador }\end{array}$ & $\begin{array}{l}\text { Productos intensivos en } \\
\text { recursos naturales }\end{array}$ & $\begin{array}{l}\text { Altos niveles de participación de } \\
\text { productos con alto valor } \\
\text { agregado e intensivos en } \\
\text { conocimiento }\end{array}$ \\
\hline \multirow{3}{*}{$\begin{array}{c}\text { Pyme } \\
\text { industriales }\end{array}$} & $\begin{array}{l}\text { Desempeño } \\
\text { interno }\end{array}$ & $\begin{array}{l}\text { Orientado al procesamiento } \\
\text { de recursos naturales e } \\
\text { intensivos en trabajo }\end{array}$ & $\begin{array}{l}\text { Participación creciente en } \\
\text { actividades industrialmente } \\
\text { dinámicas e intensivas en } \\
\text { conocimiento }\end{array}$ \\
\hline & $\begin{array}{l}\text { Participación en el } \\
\text { VA industrial }\end{array}$ & $\begin{array}{l}\text { Nivel de participación } \\
\text { decreciente }\end{array}$ & Nivel de participación creciente \\
\hline & $\begin{array}{l}\text { Desempeño } \\
\text { exportador }\end{array}$ & $\begin{array}{l}\text { Bajos niveles, asociados a } \\
\text { procesamiento de recursos } \\
\text { naturales }\end{array}$ & $\begin{array}{l}\text { Altos niveles, asociado a } \\
\text { productos industrializados con } \\
\text { alto valor agregado }\end{array}$ \\
\hline
\end{tabular}

Fuente: elaboración propia.

\section{Industria y pyme en el patrón de acumulación: el caso argentino}

En esta sección nos enfocamos en establecer cuál ha sido la evolución y características del sector industrial y las pyme y el lugar que han ocupado en el PA. Aquí es pertinente considerar y recordar lo sucedido en el período neoliberal para el caso argentino, ya que este asume cierta especificidad respecto a lo sucedido en otros países (p. ej. Brasil). Sintéticamente, podemos mencionar que el repentino y abrupto proceso de apertura y liberalización económica y financiera de la economía bajo una macroeconomía de paridad cambiaria (\$1 = US\$1), así como el proceso de privatización de las empresas que habían sido icónicas de la Argentina industrial $^{13}$, desarticularon drásticamente el entramado productivo nacional para revalorizar las ventajas naturales. Frente al efecto de "shock" desindustrializador que ello provocó durante la década de 1990 (Etchemendy 2001; Azpiazu y Schorr 2010b), el neodesarrollismo argentino significó la recomposición y mejoramiento de las condiciones de reproducción capitalista a través de apelar a la "industria nacional", a pesar de que en los hechos, y debido a la magnitud de las transformaciones, la fisonomía que esta fue adquiriendo significó la profundización de algunas características del período anterior (Féliz 2013).

13 Actualmente, con excepción de algunas empresas recuperadas por el Estado (p. ej. YPF y Fábrica de Aviones Militares) o de reciente creación (AR-SAT), las empresas estatales desempeñan un rol marginal en la economía argentina. 


\subsection{Crecimiento industrial y el carácter posneoliberal}

En este segmento, nuestro interés es establecer la forma y características que el escenario industrial fue adquiriendo a lo largo de la experiencia neodesarrollista argentina a fin de enmarcar el desempeño de las pyme que será presentado más adelante.

A modo de reflejar más adecuadamente el desempeño industrial, debemos destacar la importancia de este sector como motor de la economía durante el período 2002-2007. Luego, fue un período con mayores dificultades (2008-2010) a raíz de la crisis internacional, sumado a la emergencia de restricción externa y la pérdida de competitividad por "dólar alto" (Santarcángelo, Fal y Pinazo 2011; Schorr 2013). En el período 2002-2007, por ejemplo, el crecimiento del sector fabril (destacándose las ramas de maquinarias y equipos) logró tasas superiores a las del conjunto agregado de la economía (Santarcángelo, Fal y Pinazo 2011). Sin embargo, en el período posterior, la industria comenzó a tener mayor inestabilidad, con especial énfasis en las que habían sido los motores de la primera etapa (con la salvedad del sector automotriz), logrando profundizar el déficit en la balanza comercial del sector (Schorr 2013; Kulfas, Goldstein y Burgos 2014).

A pesar de las altas tasas de crecimiento hasta 2011 (excepto 2009), la industria no logró mejorar su posición dentro del conjunto de la economía, sino que inauguró exiguas tasa de crecimiento industrial muy por debajo de las tasas del PBI (gráfica 1). El factor central parece estar asociado a la ausencia de cambios significativos de la estructura sectorial (Porta y Fernández 2011; Santarcángelo, Fal y Pinazo 2011; Schorr 2013) y actoral, reproduciendo y profundizando ciertos rasgos estructurales del neoliberalismo.

Gráfica 1. Participación en el PBI y tasas de crecimiento del sector industrial y PBI en Argentina. Datos en porcentajes con base 1993 y base 2004

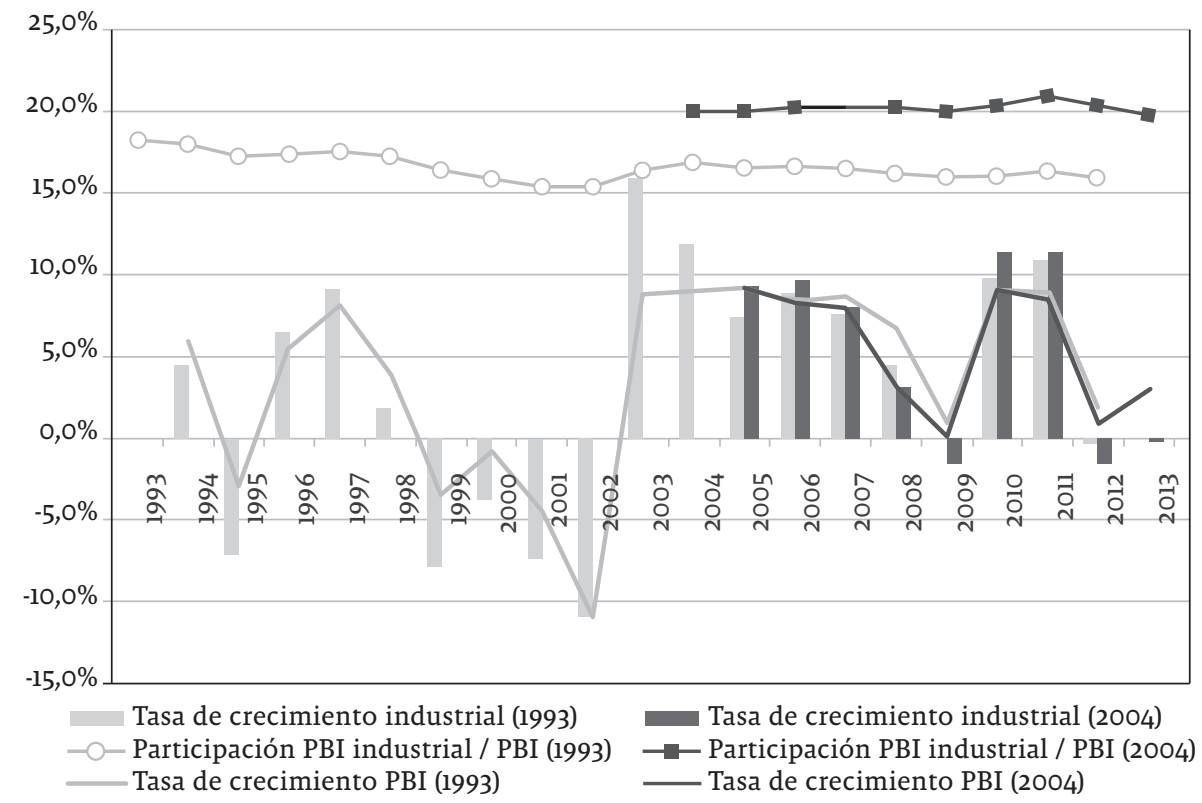

Fuente: elaboración propia con base en datos del Ministerio de Economía y Finanzas Públicas 
Desde la perspectiva actoral, el rasgo de concentración de capital tendió a profundizarse. Según Wainer y Schorr (2014), la participación de la cúpula industrial (cien empresas de mayor facturación) en el valor bruto de producción ha seguido en aumento, pasando de un promedio de $31,9 \%$ en el período neoliberal a $40,2 \%$ en el período neodesarrollista, tomando los períodos 1993-2001 y 2002-2010 respectivamente. Tomando la misma base de análisis (cien empresas), la participación de la cúpula industrial en las exportaciones industriales totales ha pasado de un promedio de $67,5 \%$ a $77,7 \%$ respectivamente para los períodos mencionados (Schorr 2013).

Sumado a este proceso, el avance del capital extranjero ha sido otro de los rasgos profundizado bajo el neodesarrollismo, dando características particulares a la concentración industrial. Por ejemplo, dentro del plantel de las 500 empresas más importantes del país (industria y otros sectores económicos) el peso relativo de las empresas extranjeras en el valor bruto de producción ha pasado de un promedio de $56 \%$ en el período neoliberal a $75,4 \%$ en el neodesarrollismo consolidando el núcleo duro del poder económico local y sobre toda la economía (Wainer y Schorr 2014). En el sector industrial, el capital extranjero participó en las exportaciones del plantel de las cien empresas industriales $30,5 \%$ en $1993,59,9 \%$ en 2002 y $68,1 \%$ en 2010 . En tanto, el peso de estas empresas (67 empresas extranjeras) en las exportaciones industriales totales de las Argentina fue de 50,8\% en 2010 (Schorr 2013).

En este escenario de profundización de la concentración y extranjerización del sector industrial, el patrón de especialización sectorial estuvo dinamizado principalmente por las ramas de actividad asociada a los recursos naturales y commodities como aquellas asociadas a los regímenes de promoción industrial (electrónicos, automotriz). Actividades como la de alimentos y bebidas, sustancias y productos químicos, fabricación de vehículos automotores, refinación de petróleo y fabricación de metales comunes (con altos niveles de concentración y participación extranjera) en 2010 generaron más de las dos terceras partes $(67,1 \%)$ del producto manufacturero (Schorr 2013; Wainer y Schorr 2014). Estos sectores, individual y conjuntamente, alcanzaron participaciones mayores que las promediadas durante el período neoliberal (60\%) (Azpiazu y Schorr 2010a). Como comentamos anteriormente, ello marcó el retroceso de actividades como la metalmecánica y el sector de bienes de capital que, luego de 2009, operaron bajo un efecto de "sustitución inversa" (Castells et al. 2014).

Por otra parte, un análisis del resultado de la dinámica exportación/importación según el contenido tecnológico de los productos nos permite establecer rápidamente un registro de la competitividad de la economía y del perfil de especialización. De acuerdo con los montos y el contenido tecnológico, en el período neodesarrollista las importaciones estuvieron concentradas en alta y mediana-alta tecnología en promedio $72,5 \%$ frente al $70,4 \%$ del período neoliberal; y las exportaciones estuvieron concentradas en baja y mediana-baja tecnología: $83,1 \%$ frente a $84,7 \%$ en los períodos respectivos (Schorr y Wainer 2013). Es decir, las exportaciones industriales aumentaron notablemente (tasa anual promedio de $13,5 \%$ ), pero estuvieron concentradas en "alimentos y bebidas" (43\%), "metales comunes" (7\%), "sustancias y productos químicos" (8\%) y "vehículos automotores" (12\%): los tres primeros basados 
en recursos naturales y el último liderado por ET (principalmente, con Brasil) (Schorr 2013). De modo que la densidad y complejidad tecnológica de la oferta exportable fue dando lugar al paulatino crecimiento del déficit comercial del sector (Belloni y Wainer 2013) ${ }^{14}$.

De esta sintética descripción se interpreta que las propiedades heredadas del período neoliberal se han profundizado. El PA presenta rasgos de reprimarización acompañados de la profundización de la concentración y extranjerización de la matriz productiva (tabla 2).

Tabla 2. Dinámica requerida y real del sector industrial en Argentina (2002-2013)

\begin{tabular}{|c|l|l|l|}
\hline \multirow{3}{*}{ Sector económico } & \multicolumn{1}{|c|}{ Características } & \multicolumn{1}{|c|}{$\begin{array}{c}\text { Dinámica posneoliberal } \\
\text { solicitada al sector industrial }\end{array}$} & $\begin{array}{l}\text { Dinámica real del sector } \\
\text { industrial }\end{array}$ \\
\cline { 2 - 4 } & Origen del capital & Mayoría endógeno & $\begin{array}{l}\text { Extranjerización } \\
\text { profundizada }\end{array}$ \\
\cline { 2 - 4 } & capital & Desconcentrado & $\begin{array}{l}\text { Concentración } \\
\text { profundizada }\end{array}$ \\
\cline { 2 - 4 } & Desempeño interno & $\begin{array}{l}\text { Participación creciente en el } \\
\text { PBI, actividades } \\
\text { industrialmente dinámicas e } \\
\text { intensivas en conocimiento }\end{array}$ & $\begin{array}{l}\text { No se aprecia aumento } \\
\text { de participación en el } \\
\text { PBI. Tendencia a } \\
\text { procesar recursos } \\
\text { naturales y commodities }\end{array}$ \\
\cline { 2 - 4 } & $\begin{array}{l}\text { nesempeño } \\
\text { exportador }\end{array}$ & $\begin{array}{l}\text { Altos niveles de } \\
\text { participación de productos } \\
\text { con alto valor agregado e } \\
\text { intensivos en conocimiento }\end{array}$ & $\begin{array}{l}\text { Profundización de la } \\
\text { tendencia a la } \\
\text { reprimarización }\end{array}$ \\
\hline
\end{tabular}

Fuente: elaboración propia.

De acuerdo con nuestro análisis, este escenario estructural caracterizado por la profundización de los principales rasgos del proyecto neoliberal asume un perfil poco proclive para cualificar el desempeño y participación de las pyme en las actividades y funciones de alto valor agregado dentro de las REG. En el siguiente apartado mostraremos de modo estilizado el comportamiento y desempeño económico de las pyme, dando cuenta de esta formulación.

\subsection{Las pyme en el escenario neodesarrollista argentino}

A pesar del reconocimiento y revalorización de la importancia de las pyme en el proceso de "reindustrialización" —al menos discursivamente y a través de diversos instrumentos y políticas públicas-, el desempeño real de estos actores no solo mostró un franco declive en sus aspectos clásicos como la creación de

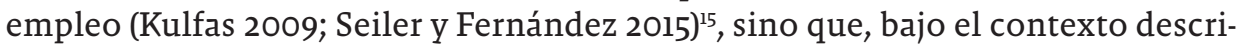

14 Cabe mencionar la posición de Argentina en el marco de las REG agroalimentarias (Anlló, Bisang y Salvatierra 2010). En la medida en que ello pueda ser densamente articulado con las dinámicas internas, será una estrategia válida para expandir el progreso técnico y propiciar el desarrollo (Sztulwark y Míguez 2012).

15 Hasta 2008, las pyme industriales creaban empleo privado registrado a tasas similares a las grandes empresas (en torno a 7 puntos); de 2009 en adelante, las pyme lo hicieron a 0,5\% mientras que las grandes a 2,5\% en promedio (Seiler y Fernández 2015). 
to anteriormente, las pyme industriales perdieron espacio en el valor agregado, se concentraron en productos de bajo contenido y difusión tecnológica perdiendo participación en el mercado externo.

En contraste con los países centrales (Cepal/OCDE 2012), uno de los elementos que sobresale en el período neodesarrollista es la pérdida del peso de las pyme en el valor agregado. Si bien no se dispone de estadísticas oficiales para precisarlo, desde lo interno, el proceso de concentración de la cúpula empresarial plantó la contracara de su caída ${ }^{16}$. También, como mostraremos más adelante, la caída de la participación fue muy notoria en el período que estamos analizando.

Esta involución de la participación de las pyme parece obedecer principalmente a las escasas transformaciones estructurales que operaron en la industria manufacturera en su conjunto, como marcan Porta y Fernandez (2011), y de allí, tampoco se produjeron transformaciones en la estructura pyme a escala sectorial. Las pyme productoras de baja tecnología mantuvieron su importancia relativa, así como las de alta tecnología continuaron representando un papel minoritario sin generarse cambios significativos en la matriz de especialización productiva (Acosta 2010; CERA 2013; Kulfas 2009).

$\mathrm{Al}$ respecto, en la gráfica 2 se muestra la evolución de la estructura pyme siguiendo la cantidad de empresas según las ramas industriales. La matriz pyme

Gráfica 2. Cantidad de empresas pyme según ramas de actividad de la industria manu-

facturera en Argentina. Participación según promedio de períodos (1996-2012)

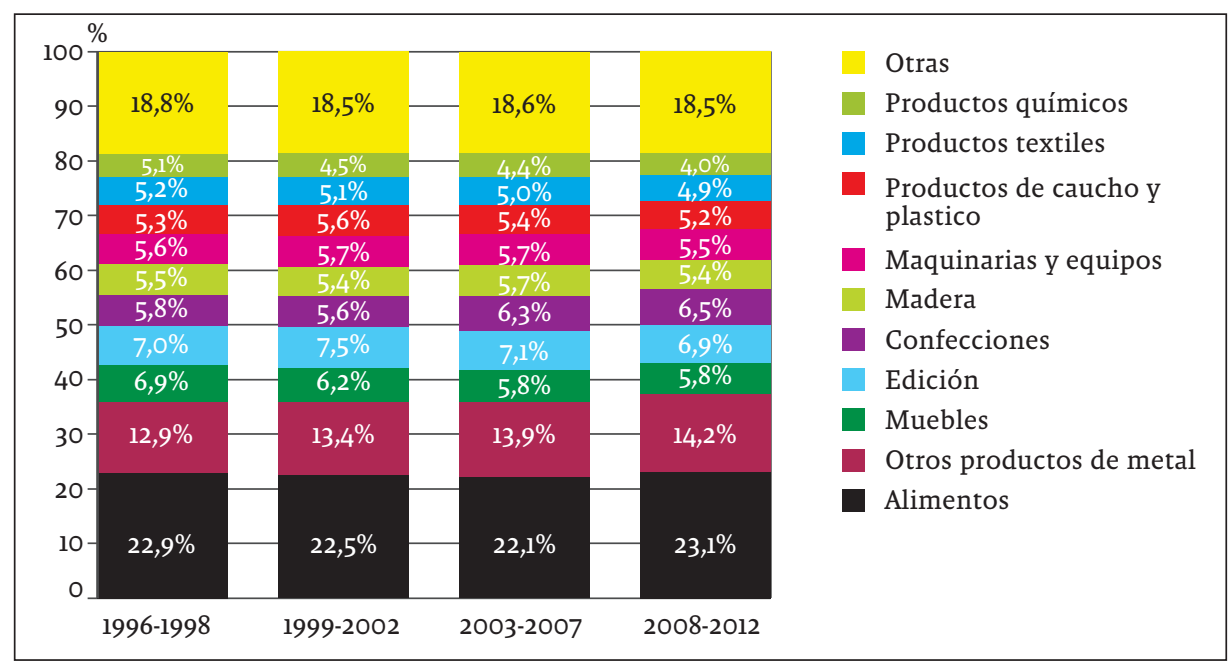

Fuente: elaboración propia con base en datos del Observatorio de Empleo y Dinámica Empresarial (2015).

16 Cabe destacar que mientras la tasa de rentabilidad de las grandes empresas en 1997-1999 era el doble que la de las pyme, en el período 2003-2006 la brecha se amplió al triple (Kulfas 2009). Por otra parte, según cálculos propios de los datos del MAPA PYME (proyecto conjunto entre la Secretaría de la Pequeña y Mediana Empresa y Desarrollo Regional y el PNUD para recolectar información referente a las pyme en Argentina), las pyme industriales participaron en el valor agregado menos de 10 puntos en promedio en 2006-2008. 
en el neodesarrollismo presenta rasgos muy similares a la desarrollada durante el período neoliberal, a pesar de cierto avance de sectores intensivos en conocimiento como el de softwares (Kulfas 2009). Si bien los datos presentados son parciales e insuficientes, ya que no hace mención a las estrategias y desempeño particular de las pyme, se puede advertir que a pesar de las altas tasas de natalidad de empresas en sectores como el mencionado (Kulfas 2009), el cuadro sectorial continuó concentrado en las ramas más tradicionales (alimentos, otros productos de metal, muebles y edición). Según la gráfica 2, la reactivación económica repercutió como un estímulo general reproduciendo más que modificando la configuración sectorial pyme. Y, por ejemplo, los sectores cargados de conocimiento e ingeniería como la fabricación de equipos, que encontraron un fuerte impulso asociado al complejo petroenergético (Kulfas 2009), quedan ligados no solo a sectores mono u oligopólicos, sino propensos a desarrollar actividades y funciones no centrales dentro de la actividad.

Desde la perspectiva de las exportaciones, entre 2003 y 2012 aproximadamente dos mil pymex ${ }^{17}$ lograron ingresar al mercado externo sumándose a las cerca de cuatro mil que ya lo venían haciendo antes de ese período. Si bien esta mayor participación numérica expresa un acontecimiento de superación del período neoliberal, cuando los datos se comienzan a desagregar, la participación pymex comienza a ser relativizada y mostrar cierto rezago en las exportaciones industriales. Dicha profundización se expresa en la pérdida de participación en el valor exportado con gran fundamento en la reprimarización de las exportaciones pymex.

En primer lugar, el número de pymex que comenzaron a exportar aumentó notablemente, sin embargo, no lograron relativizar su peso en el valor exportado. Como se muestra en la gráfica 3, la tasa de crecimiento de las grandes empresas fue exponencialmente superior a las pyme, exceptuando en 2009. En promedio, las exportaciones de las grandes empresas crecieron a una tasa de $16,9 \%$ en el período 2003-2008 y 4,7\% en el período 2009-2013, mientras que las pymex lo hicieron a una tasa de $2,2 \%$ y 0,5\% respectivamente. Desde ese punto de vista, las grandes empresas aumentaron exponencialmente el monto exportado por firma, pasando de US\$27 millones (2003) a US\$72 millones (2013), mientras que las pyme solo ascendieron de US\$0,6 millones (2003) a US\$0,90 millones (2013).

Esta dinámica plasmó un resultado desigual para las pymex industriales, ya que significó la continuidad de un proceso de caída del peso relativo de la participación de las pymex sobre el total del valor exportado del sector industrial (FOB - US\$్). Pasó de 22,2\% en 1992 (en tanto se implementaba el CW), 14,6\% en 1996, a 13,8\% en 1998, y mantuvo 12 puntos hasta el año 2003 (inicio del período neodesarrollista); en 2013 obtuvieron solo 9 puntos en el valor exportado del sector industrial (gráfica 4). Como advertimos más arriba, a pesar de no contar con datos estadísticos sistemáticos sobre las pyme, la gráfica anterior puede tomarse como ejemplo para advertir el lugar que las pyme fueron perdiendo en la estructura económica.

17 La sigla pymex es utilizada en este trabajo para nominar a la pyme exportadora del sector industrial. La clasificación del tamaño de empresas corresponde a los criterios adoptados por la Cámara de Exportadores de la República Argentina (CERA) de donde obtuvimos los datos. 
Gráfica 3. Tasa de crecimiento de las exportaciones industriales según tamaño de empresa (1995-2013). En dólares FOB

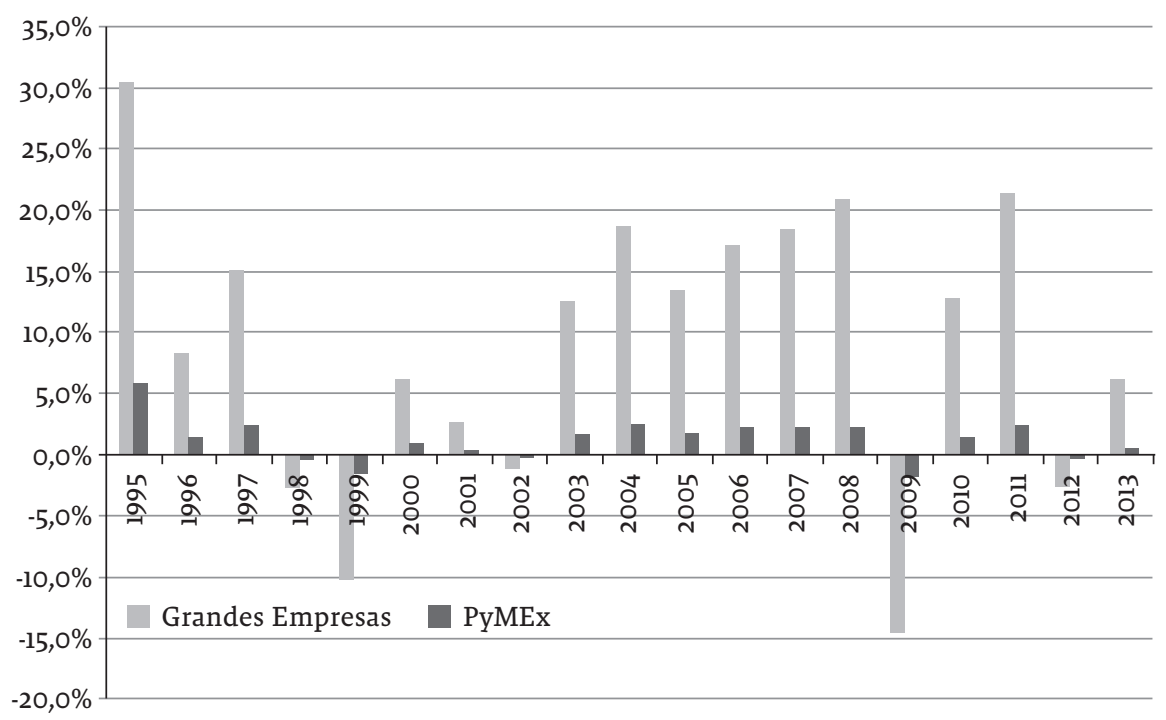

Fuente: elaboración propia con base en datos de CERA (2014).

Gráfica 4. Participación de las pymex en el valor exportado (1994-2013). En millones de dólares FOB y porcentaje

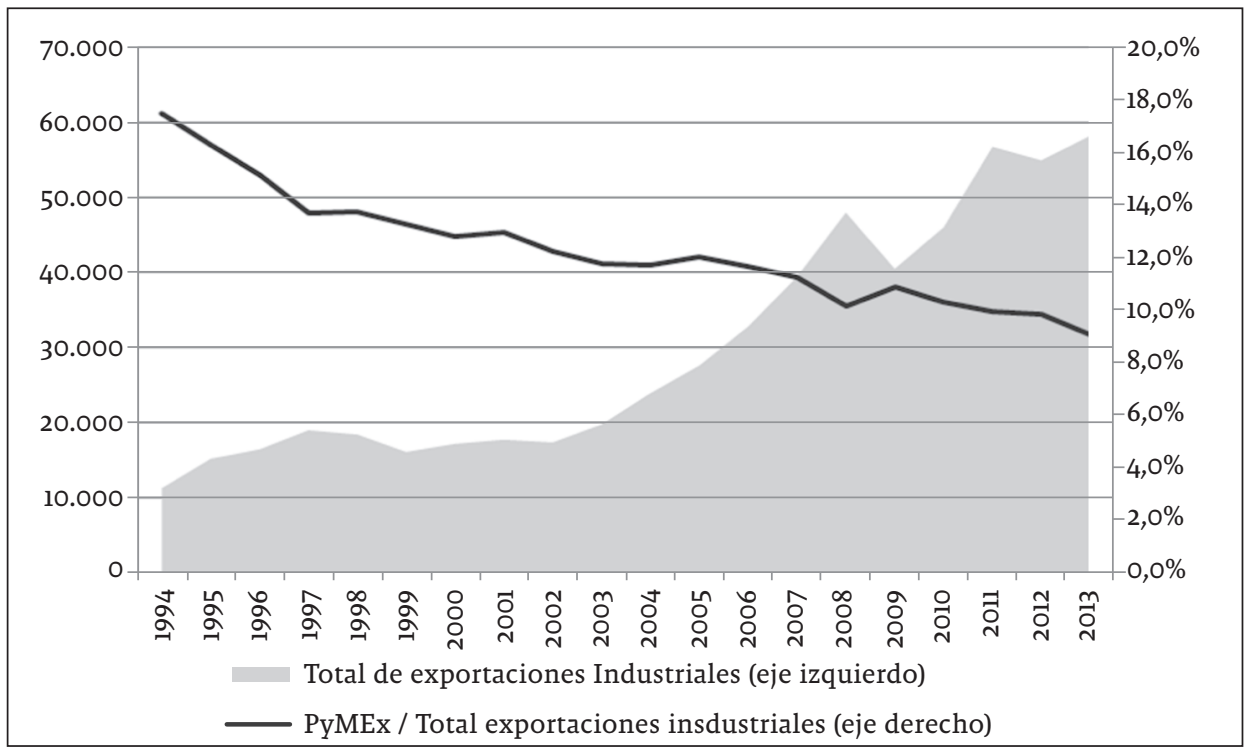

Fuente: elaboración propia con base en datos de varios informes de la Cámara de Exportadores de la República Argentina (CERA). 
Ahora bien, tomando en cuenta el requerimiento solicitado a las pyme de incursionar en actividades con alto valor agregado y capacidad de expandir el progreso técnico a través de ramas intensivas en conocimiento (p. ej. metalmecánica, equipos complejos, etc.), el período neodesarrollista provocó una notable pérdida de participación en dichas actividades, a pesar de los avances logrados a comienzos del período (Kulfas 2009). Las pymex han ganado peso en aquellas actividades relacionadas con el procesamiento de recursos naturales y/o intensivas en mano de obra (tabla 3). Mientras que en ramas como la textil y vestimenta, cuero y calzado, química y plásticos, y madera y papel aumentaron su participación (monto exportado), en ramas como la metalmecánica su peso relativo en el total exportado experimentó un descenso de más de 50\% (de 17,22\% en 2004 a 8,22\% en 2013) (tabla 3).

Tabla 3. Participación sectorial de las pymex en las exportaciones industriales 2004 y 2013. En dólares FOB

\begin{tabular}{|l|r|r|r|r|}
\hline \multicolumn{1}{|c|}{ Ramas de actividad } & $\begin{array}{c}\text { Participación } \\
\text { sectorial pymex (1) }\end{array}$ & $\begin{array}{c}\text { Participación } \\
\text { Pymex/total (2) }\end{array}$ & $\begin{array}{c}\text { Participación } \\
\text { sectorial pymex (1) }\end{array}$ & $\begin{array}{c}\text { Participación } \\
\text { pymex/total (2) }\end{array}$ \\
\hline Metalmecánica & $32,05 \%$ & $\mathbf{1 7 , 2 2} \%$ & $31,33 \%$ & $\mathbf{8 , 2 2} \%$ \\
\hline $\begin{array}{l}\text { Alimentos, bebidas y } \\
\text { tabaco }\end{array}$ & $31,69 \%$ & $8,47 \%$ & $34,31 \%$ & $6,7 \%$ \\
\hline Químicos y plásticos & $19,74 \%$ & $9,23 \%$ & $22,36 \%$ & $13,13 \%$ \\
\hline Madera y papel & $6,67 \%$ & $24,97 \%$ & $3,74 \%$ & $27,51 \%$ \\
\hline Textil y vestimenta & $4,64 \%$ & $31,55 \%$ & $3,70 \%$ & $40,88 \%$ \\
\hline Cueros y calzado & $3,64 \%$ & $10,78 \%$ & $3,36 \%$ & $16,50 \%$ \\
\hline Resto & $1,61 \%$ & $81,82 \%$ & $1,20 \%$ & $37,06 \%$ \\
\hline Total & $\mathbf{1 0 0 \%}$ & & $\mathbf{1 0 0 \%}$ & \\
\hline
\end{tabular}

\section{Notas:}

(1) Participación sectorial según la cantidad de empresas sobre el universo total de pymex.

(2) Participación de las pymex según el monto exportado sobre el monto total FOB (Free on Board) de exportación expresado en millones de dólares estadounidense.

Fuente: elaboración propia con base en datos de CERA (2014).

La pérdida de relevancia de la rama metalmecánica — con un fuerte componente de ingeniería e innovación - parece estar dada por la caída del sector de "bienes de capital" (tabla 4) donde las grandes empresas tienen un peso muy fuerte (CERA 2014). Notemos aquí que ello también está asociado al proceso de "sustitución inversa" provocado por la pérdida de competitividad y dinamismo no solo de las pyme, sino del sector industrial en su conjunto (Castells et al. 2014).

En resumen, los elementos empíricos presentados en las secciones anteriores, si bien pueden resultar insuficientes a raíz de la ausencia de datos, muestran que en un marco de transnacionalización, concentración y reprimarización del PA -en clara correspondencia a la lógica de funcionamiento de las REG-, las pyme no lograron un desempeño económico cualitativamente superior -interno como externo- ya que su condición diferenciadora y cualificadora fue subsumida a un comportamiento procíclico y subalternizador de ese PA. 
Contrastando con los requerimientos que demanda una dinámica posneoliberal en la periferia, en la tabla 5 se hace un resumen de los elementos empíricos relevados de la dinámica real de las pymes en el neodesarrollismo.

Tabla 4. Participación pymex en la rama metalmecánica, 2004 y 2013. En dólares FOB

\begin{tabular}{|l|c|c|}
\hline \multirow{2}{*}{\multicolumn{1}{c|}{ Metalmecánica }} & \multicolumn{2}{c|}{ pymex / Total exportado } \\
\cline { 2 - 3 } Bienes de consumo para el hogar & 2004 & $\mathbf{2 0 1 3}$ \\
\hline Insumos de las construcción & $41 \%$ & $62 \%$ \\
\hline Insumos y productos no específicos & $38 \%$ & $47 \%$ \\
\hline Bienes de capital & $54 \%$ & $39 \%$ \\
\hline Electrónica e instrumentos médicos & & \\
\hline Maquinarias y equipos & $\mathbf{4 8 \%}$ & $\mathbf{3 1} \%$ \\
\hline Insumos básicos & $\mathbf{6 0 \%}$ & $\mathbf{2 9} \%$ \\
\hline Automotriz & $4 \%$ & $\mathbf{2} \%$ \\
\hline
\end{tabular}

Fuente: CERA $(2014,35)$.

Tabla 5. Dinámica requerida y real de las pyme en Argentina (2002-2013)

\begin{tabular}{|c|l|l|l|}
\hline $\begin{array}{c}\text { Sector } \\
\text { económico }\end{array}$ & \multicolumn{1}{|c|}{ Características } & $\begin{array}{c}\text { Dinámica posneoliberal } \\
\text { requerida a los actores pyme }\end{array}$ & \multicolumn{1}{c|}{$\begin{array}{c}\text { Dinámica real del sector } \\
\text { pyme (2002-2013) }\end{array}$} \\
\hline \multirow{3}{*}{$\begin{array}{l}\text { Pyme } \\
\text { industriales }\end{array}$} & $\begin{array}{c}\text { Participación en el } \\
\text { valor agregado }\end{array}$ & $\begin{array}{l}\text { Participación creciente en } \\
\text { actividades industrialmente } \\
\text { dinámicas e intensivas en } \\
\text { conocimiento }\end{array}$ & $\begin{array}{l}\text { Caída en sectores } \\
\text { industrialmente dinámicos e } \\
\text { intensivos en conocimiento } \\
\text { creciente }\end{array}$ \\
\cline { 2 - 4 } & $\begin{array}{l}\text { Desempenticipación } \\
\text { exportador }\end{array}$ & $\begin{array}{l}\text { Altos niveles de } \\
\text { participación, asociado a } \\
\text { productos con alto valor } \\
\text { agregado e intensivos en } \\
\text { conocimiento }\end{array}$ & $\begin{array}{l}\text { Participación decreciente } \\
\text { Orientado a procesar } \\
\text { recursos naturales } \\
\text { Descenso en sectores } \\
\text { intensivos en conocimiento }\end{array}$ \\
\hline
\end{tabular}

Fuente: elaboración propia.

\section{Conclusiones}

El propósito de este artículo fue resituar la discusión acerca del papel estratégico del sector industrial y los actores pyme en los procesos de acumulación en Latinoamérica a inicio del Siglo XXI. Destacamos que la relevancia de este sector y esos actores debía ser precisada en el marco de la interrelacionada y disputada configuración del PA nacional y su vinculación con las transformaciones recientes del capitalismo y la lógica neoliberal de los actores transnacionales que las comandan.

Hemos evaluado críticamente los requerimientos y desafíos que pesan sobre la industria y los actores pyme para conformar un PA capaz de alinear los proyectos neodesarrollistas con una modalidad posneoliberal de acumulación en ese escenario disputado. Ante el dominio del PA periférico, en cuya conformación 
las fracciones globalizadas del capital propugnan la profundización de sus formas concentradas, extranjerizadas y reprimarizadas, destacamos la necesidad de una conformación más compleja, endógena y desconcentrada como propiedades alternativas y requeridas para dar a esos proyectos neodesarrollistas capacidad de superar el escenario neoliberal de fragmentación y subordinación que imponen internamente aquellas fracciones.

En tal contexto, y en relación con la contribución a esas propiedades del PA, en la que hemos destacado el rol estratégico del sector industrial y de los actores pyme, propusimos interpelar nuestro marco conceptual a partir de un análisis de la dinámica interna y externa de ese sector y esos actores en la experiencia argentina. En dicha evaluación, marcamos las dificultades en cuanto a la emergencia de esas propiedades alternativas comprobando que el PA, lejos de adoptar un comportamiento alternativo a aquella forma de inserción periférica y subordinada, se ha caracterizado por su compatibilidad con $-\mathrm{y}$ en obediencia a- las lógicas e intereses reproductivos del capital transnacional. Allí, tanto el sector industrial como las pyme continuaron desempeñando un rol visiblemente marginal y subalterno, que no reflejó alteraciones significativas respecto al papel desempeñado durante el CW. La inalteración -y en algunos casos profundización- de los rasgos periféricos del PA —concentración, transnacionalización y reprimarización- condicionaron el comportamiento de las pyme y cerraron el espacio para transformar su subalternidad tanto en su dinámica interna como externa.

Por una parte, la verificación de este comportamiento subalterno incorpora dimensiones cualitativas nuevas puesto que marca las restricciones que poseen como actores cuando se ausentan los requerimientos -inicialmente presentados- que recaen sobre el PA para formar un proceso de desarrollo posneoliberal. Por tanto, la cualificación del desempeño de las pyme no puede encontrar sus causas aisladamente de su interacción con las jerárquicas y disputadas relaciones que conforman el PA. En tal escenario, fundamentamos su contribución a la conformación de un PA alternativo - más endógeno, complejo y dinámico一, así como, desde el plano socio-político, su aporte a la configuración de una base coalicional socio-espacialmente más desconcentrada.

Por otra parte, la indagación de las causas de la inconcreción de estas propiedades en el caso argentino, y por tanto la continuidad antes que la transformación del PA neoliberal consolidado bajo el CW, demanda incorporar nuevos elementos analíticos, situándose entre ellos al Estado como actor y escenario estratégico del proceso conflictual de la acumulación capitalista. En tal sentido, un avance conceptual y metodológico, así como una indagación empírica sobre las propiedades/calidades de las estructuras y formas implicativas del Estado en el disputado escenario de la formación del PA, se presenta como uno de los principales imperativos para una agenda consistente de investigación a futuro, orientada a explorar las formas más adecuadas de impulsar exitosamente, en el escenario latinoamericano, un PA alternativo en el que las pyme logren actuar como vehículos no secundarios de esa disputada configuración. 


\section{Referencias bibliográficas}

Acosta, Silvia. «Las PyMI argentina en el escenario postconvertibilidad». Boletín Informativo Techint, $\mathrm{n}^{\mathrm{O}}$ 332, 2010: 81-104. Disponible en: http://goo.gl/d2v3uK (último acceso: 05 de mayo de 2015).

Amsden, Alice. Asia's Next Giant. South Korea and Late Industrialization. Nueva York: Oxford University Press, 1989.

Amsden, Alice. The Rise of "The Rest". Challenges to the West from Late-Industrializing Economies. Nueva York: Oxford University Press, 2001.

Amsden, Alice. «La sustitución de importaciones en la industria de alta tecnología: Prebisch renace en Asia». Revista de la Cepal, no 82, 2004: 75-90. Disponible en: http://goo.gl/Sl2Hma (último acceso: 20 de abril de 2015).

Anlló, Guillermo, Roberto Bisang y Guillermo Salvatierra. Cambios estructurales en las actividades agropecuarias. De lo primario a las cadenas globales de valor. Santiago de Chile: Cepal, 2010. Disponible en: http://goo.gl/LYLuce (último acceso: 15 de septiembre de 2015).

Azpiazu, Daniel, Eduardo Basualdo y Martín Schorr. La industria argentina durante los años noventa: profundización y consolidación de los rasgos centrales de la dinámica sectorial post-sustitutiva. S/c: Flacso, Área de Economía y Tecnología, 2001. Disponible en: http://goo.gl/XQta2B (último acceso: 05 de mayo de 2015).

Azpiazu, Daniel y Martín Schorr. Hecho en Argentina: industria y economía, 19762007. Buenos Aires: Siglo Veintiuno Editores, 2010 a.

Azpiazu, Daniel y Martín Schorr. «La industria argentina en la posconvertibilidad: reactivación y legados del neoliberalismo». Problemas del desarrollo, Vol. 41, $\mathrm{n}^{\circ}$ 161, 2010b: 1ll-139.

Baldwin, Richard. «Trade and Industrialisation After Globalisation's 2nd Unbundling: How Building and Joining a Supply Chain are Different and Why it Matters». NBER Working Paper, $\mathrm{n}^{\circ}$ 17716, 2011: 1-38. Disponible en: http://goo.gl/ x4Y27F (último acceso: 05 de mayo de 2015).

Basualdo, Eduardo. «Entre la dolarización y la devaluación: la crisis de la convertibilidad en Argentina». Íconos: Revista de Ciencias Sociales, $\mathrm{n}^{\circ}$ 13, 2002: 14-20. doi: http://dx.doi.org/10.17141/iconos.13.2002.612.

Basualdo, Eduardo. Estudios de historia económica argentina: desde mediados del siglo XX a la actualidad. Buenos Aires: Flacso, 2006.

Bekerman, Marta, Marcelo Wiñazky y Nicolás Moncaut. «Políticas productivas para fortalecer la inserción internacional de las empresas PYMES: los consorcios de exportación en Argentina». Revista Integración y Comercio, Vol. 37, $\mathrm{n}^{\circ}$ 17, 2013: 57-73. Disponible en: http://goo.gl/aaeeIY (último acceso: 6 de mayo de 2015).

Bell, Daniel. El advenimiento de la sociedad post-industrial: un intento de prognosis social. Madrid: Alianza Editorial, 1976.

Belloni, Paula y Andrés Wainer. «La continuidad de la dependencia bajo nuevas formas: la relación entre la restricción externa y el capital extranjero en la Argentina». Cuadernos del CENDES, nº 83, 2013: 23-51.

Cámara de Exportadores de la República Argentina (CERA). Las PyMEX Argentinas. Mapa Regional. Año 2012. 2013. Disponible en: www.cera.org.ar (último acceso: 05 de mayo de 2015). 
Cámara de Exportadores de la República Argentina (CERA). Las PyMEX en la década 2004-2013. 2014. Disponible en: www.cera.org.ar (último acceso: 05 de mayo de 2015).

Castellani, Ana y Alejandro Gaggero. «La retirada heterogénea: estrategias y desempeños de los grupos económicos nacionales en la Argentina de la década de 1990». Apuntes: Revista de Ciencias Sociales, Vol. 39, nº 70, 2012: 203-238.

Castellani, Ana y Martín Schorr. «Argentina: convertibilidad, crisis de acumulación y disputas en el interior del bloque de poder económico». Cuadernos del CENDES, Vol. 21, $\mathrm{n}^{\circ}$ 57, 2004: 55-81.

Castells, María, Esteban Ferreira, Eugenia Inchauspe y Martín Schorr. «Bienes de capital en la posconvertibilidad: desempeño comercial externo y (des)aprovechamiento de la masa crítica existente». Realidad Económica, Vol. 283, 2014: 127-158.

Comisión Económica para América Latina y el Caribe (Cepal). Panorama social de América Latina 2004. Santiago de Chile: Cepal, 2005. Disponible en: http://goo. gl/Tkl7SZ (último acceso: 5 de mayo de 2015).

Comisión Económica para América Latina y el Caribe (Cepal). Cambio estructural para la igualdad. Una visión integrada del desarrollo. Santiago de Chile: Naciones Unidas, 2012. Disponible en: http://goo.gl/KXwmYq (último acceso: 5 de mayo de 2015).

Comisión Económica para América Latina y el Caribe (Cepal) / Organización para la Cooperación y el Desarrollo Económicos (OCDE). Perspectivas económicas para América Latina: políticas de PyMEs para el cambio estructural. París: OCDE Publishing, 2012. Disponible en: http://goo.gl/GRP37y (último acceso: 5 de mayo de 2015).

Cimoli, Mario. Heterogeneidad estructural, asimetrías tecnológicas y crecimiento en América Latina. Santiago de Chile: Cepal/BID, 2005.

Cimoli, Mario, Giovanni Dosi y Joseph Stiglitz. Industrial Policy and Development, the Political Economy of Capabilities Accumulation. Nueva York: Oxford University Press, 2009.

Cohen, Stephen y John Zysman. Manufacturing Matters: The Myth of the Post-Industrial Economy. Nueva York: Basic Books (AZ), 1987.

De Matos, Marcelo y Ana Arroio. «Políticas de apoyo a micro y pequeñas empresas en Brasil: avances recientes y perspectivas». En Apoyando a las pymes: políticas de fomento en América Latina y el Caribe, editado por Carlo Ferraro, 77-164. Santiago de Chile: Cepal/AECID, 2011.

Diamand, Marcelo. «La estructura productiva desequilibrada. Argentina y el tipo de cambio». Desarrollo Económico, Vol. 12, n 45, 1972: 25-47.

Dicken, Peter, Philip Kelly, Kelly Olds y Henry Wai-Chung Yeung. «Chains and Networks, Territories and Scales: Towards a Relational Framework for Analysing the Global Economy». Global Networks, Vol. 1, nº 2, 2001: 89-112. doi: http://dx. doi.org/10.1111/1471-0374.00007.

Esser, Klaus. «América Latina. Industrialización sin visión». Nueva Sociedad, $\mathrm{n}^{\circ} 125$, 1993: $27-46$.

Etchemendy, Sebastián. "Construir coaliciones reformistas: La política de las compensaciones en el camino argentino hacia la liberalización económica». Desarrollo económico, Vol. 40, $\mathrm{n}^{\circ}$ 160, 2001: 675-706. 
Fajnzylber, Fernando. «La empresa internacional en la industrialización en América Latina». Comercio Exterior, Vol. 22, nº 4, 1972: 324-338.

Fajnzylber, Fernando. «Intervención, autodeterminación e industrialización en América Latina». El Trimestre Económico, Vol. 50, nº 197, 1983a: 307-328.

Fajnzylber, Fernando. La industrialización trunca de América Latina. México D.F.: Editorial Nueva Imagen, 1983b.

Fajnzylber, Fernando. «Reflexiones sobre las particularidades de América Latina y el sudeste asiático y sus referencias en el mundo industrializado». Investigación Económica, Vol. 46, nº 180, 1987: 63-109.

Fajnzylber, Fernando. «Industrialización en América Latina. De la "caja negra" al "casillero vacío"». Nueva Sociedad, Vol. 12, n 48, 1992: 21-28.

Faletto, Enzo. «La especificidad del Estado en América Latina». Revista Estudios, $\mathrm{n}^{\circ}$ 31, 2014: 205-236.

Féliz, Mariano. «Sin clase. Neodesarrollismo y neoestructuralismo en Argentina (2002-2011)». Século XXI-Revista de Ciências Sociais, Vol. 2, n 2, 2013: 09-43. doi: http://dx.doi.org/10.5902/223667257925.

Féliz, Mariano. «Neo-developmentalism, Accumulation by Dispossession and International Rent-Argentina, 2003-2013». International Critical Thought, Vol. 4, $n^{\circ}$ 4, 2014: 499-509. doi: http://dx.doi.org/10.1080/21598282.2014.954251.

Féliz, Mariano. «Limits and Barriers of Neodevelopmentalism Lessons from the Argentinean Experience, 2003-2011". Review of Radical Political Economics, Vol. 47, $\mathrm{n}^{\circ}$ 1, 2015: 70-89. doi: http://dx.doi.org/10.1177/0486613413518729.

Fernández, Víctor. «Global Value Chains in Global Political Networks: Tool For Development or Neoliberal Device?». Review of Radical Political Economics, Vol. 47, $\mathrm{n}^{0}$ 2, 2015: 209-230. doi: http://dx.doi.org/10.1177/0486613414532769.

Fernández, Víctor, María Alfaro y Federico Brasca. «Políticas para PyMEs en el sistema social de producción argentino post-crisis. ¿Re-colocando al Estado en el primer plano?». Semestre Económico, Vol. 14, nº 30, 2011: 13-36.

Furtado, Celso. Teoría y política del desarrollo económico. México D.F.: Siglo Veintiuno Editores, 1974.

Gereffi, Gary, Timothy Sturgeon y John Humphrey. «The Governance of Global Value Chains». Review of International Political Economy, Vol. 12, $\mathrm{n}^{\circ}$ 1, 2005: 78-104. doi: http://dx.doi.org/10.1080/09692290500049805.

Grugel, Jean y María Riggirozzi. "The Return of the State in Argentina». International Affairs, Vol. 83, $\mathrm{n}^{\mathrm{o}}$ 1, 2007: 87-107. doi: http://dx.doi. org/10.1111/j.1468-2346.2007.00604.x.

Grugel, Jean y María Riggirozzi. «Post-Neoliberalism in Latin America: Rebuilding and Reclaiming the State after Crisis». Development and Change, Vol. 43, $\mathrm{n}^{\circ} \mathrm{l}$, 2012: 1-21. doi: http://dx.doi.org/10.1111/j.1467-7660.2011.01746.x.

Harvey, David. «El "nuevo" imperialismo: acumulación por desposesión». Social Register, Vol. 40, 2004: 99-129. Disponible en: http://goo.gl/KpDbEs (último acceso: 7 de abril de 2015).

Hikino, Takashi, Alice Amsden y Leandro Wolfson. «La industrialización tardía en perspectiva histórica». Desarrollo Económico, Vol. 35, nº 137, 1995: 3-34.

Humphrey, John y Hubert Schmitz. «How Does Insertion in Global Value Chains Affect Upgrading in Industrial Clusters?». Regional Studies, Vol. 36, $\mathrm{n}^{\circ}$ 9, 2002: 1017-1027. doi: http://dx.doi.org/10.1080/0034340022000022198. 
Jenkins, Rhys. «The Political Economy of Industrialization: A Comparison of Latin American and East Asian Newly Industrializing Countries». Development and Change, Vol. 22, $\mathrm{n}^{\circ}$ 2, 1991: 197-231. doi: http://dx.doi.org/10.1080/003434002200 0022198.

Kaplinsky, Raphael. «Globalisation and Unequalisation: What Can Be Learned from Value Chain Analysis?». Journal of Development Studies, Vol. 2, nº 37, 2000: $117-146$.

Kaufman, Robert. «Cambio industrial y gobierno autoritario en América Latina: un análisis concreto del modelo burocrático-autoritario». En El nuevo autoritarismo en América Latina, editado por David Collier, 169-258. México D.F.: Fondo de Cultura Económica, 1985.

Kay, Cristóbal. «Reforma agraria, industrialización y desarrollo: ¿Por qué Asia Oriental superó a América Latina?». Debate Agrario, nº 34, 2002: 45-94.

Kohli, Atul. State-Directed Development: Political Power and Industrialization in the Global Periphery. Cambridge, Nueva York: Cambridge University Press, 2004.

Kulfas, Matías. Las PYMES argentinas en el escenario post convertibilidad: políticas públicas, situación y perspectivas. Santiago de Chile: Cepal, 2009. Disponible en: http://goo.gl/dPrf6x (último acceso: 23 de abril de 2015).

Kulfas, Matías, Evelin Goldstein y Martín Burgos. «Dinámica de la producción industrial y la sustitución de importaciones. Reflexiones históricas y balance del período 2003-2013». Documento de Trabajo Cefidar, no 64 (diciembre 2014): 1-115. Disponible en: http://goo.gl/XFgKAl (último acceso: 20 de septiembre 2015).

Levy, David. «Political Contestation in Global Production Networks». Academy of Management Review, Vol. 33, no 4, 2008: 943-962. doi: http://dx.doi.org/10.5465/ AMR.2008.34422006.

Mancini, Matías y Pablo Lavarello. «Heterogeneidad estructural: origen y evolución del concepto frente a los nuevos desafíos en el contexto de la mundialización del capital». Entrelíneas de la Política Económica, Vol. 6, n 37, 2013: 28-34

Milberg, William. «Shifting Sources and Uses of Profits: Sustaining US Financialization with Global Value Chains». Economy and Society, Vol. 37, n 3, 2008: 420451. doi: http://dx.doi.org/10.1080/03085140802172706.

Ministerio de Economía y Finanzas Públicas. www.mecon.gov.ar (último acceso: 12 de agosto de 2015).

Newman, Susan. «Financialisation and Changes in the Social Relations Along Commodity Chains: The Case of Coffeem. Review of Radical Political Economics, Vol. 41, no 4, 2009: 539-559. doi: http://dx.doi.org/10.1177/0486613409341454.

Observatorio de Empleo y Dinámica Empresarial. www.trabajo.gob.ar (último acceso: 23 de agosto de 2015).

O’Donnell, Guillermo. El Estado burocrático autoritario 1966-1973: triunfos, derrotas y crisis. Buenos Aires: Prometeo Libros, 2009.

Organización Internacional del Trabajo (OIT). Políticas para la formalización de las micro y pequeñas empresas. S/c: OIT, FORLAC, 2014. Disponible en: http://goo.gl/ Szn3qA (último acceso: 05 de mayo de 2015).

Peck, Jamie. «Economías políticas de escalas: políticas rápidas, relaciones interescalares y workfare neoliberal». En Escalas y Políticas de desarrollo regional. Desafíos para América Latina, editado por Víctor Ramiro Fernández y Carlos Brandao, 77-120. Buenos Aires: Miño y Dávila, 2010. 
Pempel, Thomas. «The Developmental Regime in a Changing World Economy». En The Developmental State, editado por Meredith Woo-Cummings, 137-181. Ithaca y Londres: Cornell University Press, 1999.

Pietrobelli, Carlo y Roberta Rabellotti. Upgrading to Compete. Global Value Chains, Clusters, and SMEs in Latin America. Washington: BID, 2006. Disponible en: https://goo.gl/FvM4MS (último acceso: 21 de abril de 2015).

Pinto, Aníbal. «Naturaleza e implicaciones de la "heterogeneidad estructural" de la América Latina». El trimestre económico, Vol. 37, nº 145(1), 1970: 83-100.

Pinto, Aníbal. «Notas sobre los estilos de desarrollo en América Latina». Revista de la Cepal, $\mathrm{n}^{\circ}$ 1, 1976: 97-128.

Piore, Michael y Charles Sabel. The Second industrial Divide. Nueva York: Basic books, 1984 .

Porta, Fernando y Cecilia Fernández. «La industria manufacturera: trayectoria reciente y cambio estructural». En La Argentina del largo plazo: crecimiento, fluctuaciones y cambio estructural, editado por PNUD, 85-125. Buenos Aires: PNUD, 2011. Disponible en: http://goo.gl/DtT5cf (último acceso: 18 de septiembre de 2015).

Prebisch, Raúl. Capitalismo periférico. Crisis y transformación. México D.F.: Fondo de Cultura Económica, 1981.

Prebisch, Raúl. «El desarrollo económico de la América Latina y algunos de sus principales problemas». Desarrollo Económico, Vol. 26, nº 103, 1986: 479-502.

Robinson, William. Latin America and Global Capitalism: A Critical Globalization Perspective. Baltimore: Johns Hopking University Press, 2008.

Rodríguez, Octavio. «Heterogeneidad estructural y empleo». Revista de la Cepal, Vol. 70, 1998: 315-321. Disponible en: http://goo.gl/qb4LI3 (último acceso: 15 de marzo de 2015).

Sader, Emir. Posneoliberalismo en América Latina. Vol. 4. Buenos Aires: Clacso, 2008. Disponible en: http://goo.gl/C7wmRA.

Salama, Pierre. «Deudas y dependencia financiera del Estado en América Latina». En Confrontaciones monetarias: marxistas y post-keynesianos en América Latina, editado por Clacso, 101-122. Buenos Aires: Clacso, 2006. Disponible en: http:// goo.gl/t3ikhu (último acceso: 20 de septiembre de 2015).

Salvia, Sebastián. «Empresarios, convertibilidad y crisis. ¿Entre la dolarización y la devaluación?». Íconos - Revista de Ciencias Sociales, Vol. 18, nº 50, 2014: 177-193. doi: http://dx.doi.org/10.17141/iconos.50.2014.1436.

Santarcángelo, Juan, Juan Fal y Germán Pinazo. «Los motores del crecimiento económico en la Argentina: rupturas y continuidades». Investigación económica, Vol. 70, $\mathrm{n}^{\circ}$ 275, 2011: 93-114.

Sassen, Saskia. «Global Inter-City Networks and Commodity Chains: Any Intersections?». Global Networks, Vol. 10, ${ }^{\circ}$ 1, 2010: 150-163.

Schorr, Martín. Argentina en la posconvertibilidad. ¿Crecimiento o desarrollo industrial? Buenos Aires: Miño y Dávila, 2013.

Schorr, Martín y Andrés Wainer. «Inserción de la industria argentina en el mercado mundial: perfil de especialización según densidad tecnológica de los productos». En Argentina en la posconvertibilidad: ¿desarrollo o crecimiento industrial?, editado por Martín Schorr, 117-144. Buenos Aires: Miño y Dávila, 2013. 
Seiler, Cristhian y Víctor Fernández. «Las PyMEs en la era neo-desarrollista y ( $(\dot{)}$ las herramientas para el desarrollo (?)». Pymes, Innovación y Desarrollo, Vol. 3, $\mathrm{n}^{\circ} \mathrm{l}$, 2015: 30-53.

Shapiro, Helen y Juan Moreno-Brid. «Alice Amsden's Impact on Latin America». Revista de Economia Política, Vol. 34, nº 2, 2014: 187-197.

Sistema Económico Latinoamericano y del Caribe (Sela). Cadenas de valor, PYMES y políticas públicas. Experiencias internacionales y lecciones para América Latina y el Caribe. Caracas: Sela, 2012. Disponible en: http://goo.gl/K6KHib (último acceso: 5 de mayo de 2015).

Stezano, Federico. «Políticas para la inserción de las microempresas y las pequeñas y medianas empresas en cadenas globales de valor en América Latina». En Estudios y Perspectivas, 1-61. México D.F.: Cepal, 2013. Disponible en: http://goo. gl/jXddlq (último acceso: 23 de abril de 2015).

Sunkel, Osvaldo. «Capitalismo transnacional y desintegración nacional». Estudios Internacionales, Vol. 4, $\mathrm{n}^{\circ}$ 16, 1971: 3-61.

Sztulwark, Sebastián y Pablo Míguez. «Conocimiento y valorización en el nuevo capitalismo». Realidad Económica, $\mathrm{n}^{\circ} 270$ (agosto-septiembre 2012): 11-32. Disponible en: http://goo.gl/SNvWlD (último acceso: 15 de septiembre de 2015).

Tyson, Laura. Why Manufacturing Still Matters. 2012. Disponible en: http://goo.gl/ QmiLwL (último acceso: 4 de mayo de 2015).

UNCTAD. Integrating Developing Countries' SMEs into Global Value Chains. 2010. Disponible en: http://goo.gl/UZLFlo (último acceso: 2 de mayo de 2015).

Wade, Robert. El mercado dirigido: la teoría económica y la función del gobierno en la industrialización del Este de Asia. México D.F.: Fondo de Cultura Económica, 1999.

Wainer, Andrés y Martín Schorr. Concentración y extranjerización del capital en la Argentina reciente: ¿Mayor autonomía nacional o incremento de la dependencia?. Latin American Research Review, Vol. 49, nº 3, 2014: 103-125. doi: http:// dx.doi.org/10.1353/lar.2014.0044. 